\title{
A false-pouch closure technique with an intact superior peroneal retinaculum for recurrent dislocation of the peroneal tendon
}

\author{
Tomohiro Matsui ${ }^{1}$ [D, Tsukasa Kumai ${ }^{2 *}$, Yasushi Shinohara ${ }^{3}$, Noriyuki Kanzaki ${ }^{4}$, Koji Noguchi $^{5}$, Hirofumi Tanaka ${ }^{6}$, \\ Takeshi Sugimoto ${ }^{7}$, Hiroki Yabiku ${ }^{2}$ and Ichiro Higashiyama ${ }^{8}$
}

\begin{abstract}
Purpose: To evaluate the usefulness of the false-pouch closure technique with an intact superior peroneal retinaculum (SPR).

Methods: From 2016 to 2020, 30 patients with recurrent dislocation of the peroneal tendon were treated with the current procedure. Clinical outcomes, including the time to resume running, the rate and time to return to sports, and the American Orthopaedic Foot and Ankle Society (AOFAS) Ankle-Hind Foot score, were evaluated preoperatively and at the last follow-up.

Results: The rate of return to the pre-injury level of sports activity was $93.3 \%$, and the mean duration to return to running and sports was $8.0 \pm 2.8$ weeks (range: $3-12$ weeks) and 14.4 \pm 3.2 weeks (range: 10-24 weeks), respectively. The mean preoperative AOFAS score was $79.7 \pm 9.6$ points (range: $41-90$ ), which improved significantly to $98.9 \pm 3.2$ $(87-100)$ postoperatively $(p<0.01)$.

Conclusion: The false-pouch closure technique with suture tape and anchors had a reliable clinical outcome and can enable the early return of patients to their sports activities.
\end{abstract}

Level of evidence: IV, Case series

Keywords: Peroneal tendon, Dislocation, Reattachment, False pouch

\section{Background}

Dislocation of the peroneal tendon is as a result of injury to the superior peroneal retinaculum (SPR) or avulsion fracture at the attachment site of the SPR to the fibula; this injury is often related to sports activities. The failure rate of conservative treatment for acute dislocation of the peroneal tendon is reported to be approximately $50 \%$. It is known to further result in recurrent dislocation. Previous studies have reported that in most patients with recurrent dislocation, false pouches made on the lateral

\footnotetext{
*Correspondence: kumakumat@waseda.jp

2 Faculty of Sports Sciences, Waseda University, 2-579-15 Mikajima,

Tokorozawa city, Saitama, Japan

Full list of author information is available at the end of the article
}

malleolus often responded poorly to conservative treatment. Surgical treatment is required for symptomatic recurrent dislocation $[14,25]$. Das De et al. reported an anatomical SPR reattachment procedure and preferable clinical outcomes [3]. Although an excellent clinical outcome was reported for the reattachment procedure, Cho et al. reported recurrence in one patient after SPR reattachment and mentioned that loose suturing of the SPR may cause recurrence [3]. It is important to improve the initial strength by fixing the SPR so that postoperative treatment can be accelerated, resulting in early return to sports activity. The purpose of this study was to report the technique of false-pouch closure with suture tape and anchors and its short term clinical outcomes. 


\section{Methods}

The study data were retrospectively collected from multicentre databases. A total of 30 patients were treated with the current procedure from 2016 to 2020 by six surgeons at these centres. There were 19 men and 11 women. The right foot was affected in 10 patients; and the left foot, in 20. The mean age was $22.0 \pm 8.4$ years (range: 14-42 years), and the mean follow-up duration was $10.8 \pm 6.2$ months (range: $2-33$ months). The cause of all injuries was related to sports activities, as shown in Table 1. The inclusion criteria for this study were recurrent dislocation of the peroneal tendon without any bony fragment and torn retinaculum. The indication of the current procedure was type 1 of Oden's classification (Table 2), in which the SPR is still attached to the periosteum of the lateral malleolus; however, the periosteum is elevated from the underlying malleolus and makes a false-pouch [19]. The cases in which the SPR avulsed

Table 1 Patients' characteristics

\begin{tabular}{|c|c|c|c|c|c|}
\hline Case & Age (y) & Sex & Affected side & Sports & $\begin{array}{l}\text { Follow-up } \\
\text { (Months) }\end{array}$ \\
\hline 1 & 20 & $F$ & L & Volleyball & 33 \\
\hline 2 & 16 & M & L & Soccer & 6 \\
\hline 3 & 31 & M & L & Soccer & 2 \\
\hline 4 & 16 & M & L & Basketball & 12 \\
\hline 5 & 17 & M & L & Basketball & 16 \\
\hline 6 & 17 & M & R & Soccer & 18 \\
\hline 7 & 16 & $\mathrm{~F}$ & L & Basketball & 10 \\
\hline 8 & 42 & M & L & Karate & 7 \\
\hline 9 & 15 & $F$ & L & Basketball & 7 \\
\hline 10 & 20 & $F$ & L & Soccer & 17 \\
\hline 11 & 37 & M & L & Triathlon & 14 \\
\hline 12 & 27 & $\mathrm{~F}$ & R & Skiing & 8 \\
\hline 13 & 38 & M & $\mathrm{R}$ & Baseball & 6 \\
\hline 14 & 15 & $F$ & L & Tennis & 18 \\
\hline 15 & 22 & M & L & Rugby & 19 \\
\hline 16 & 19 & M & L & Rugby & 12 \\
\hline 17 & 20 & M & $\mathrm{R}$ & Rugby & 12 \\
\hline 18 & 17 & $\mathrm{~F}$ & L & Badminton & 6 \\
\hline 19 & 19 & M & L & Rugby & 12 \\
\hline 20 & 19 & $\mathrm{~F}$ & R & Gymnastics & 7 \\
\hline 21 & 21 & M & $\mathrm{R}$ & Badminton & 18 \\
\hline 22 & 23 & M & $\mathrm{R}$ & Rugby & 12 \\
\hline 23 & 19 & M & $\mathrm{R}$ & Table tennis & 9 \\
\hline 24 & 15 & $\mathrm{~F}$ & $R$ & Soccer & 6 \\
\hline 25 & 15 & $F$ & L & Soccer & 6 \\
\hline 26 & 14 & $\mathrm{~F}$ & L & Basketball & 6 \\
\hline 27 & 15 & M & $\mathrm{R}$ & Baseball & 6 \\
\hline 28 & 41 & M & L & Skiing & 6 \\
\hline 29 & 18 & M & L & Baseball & 6 \\
\hline 30 & 36 & M & L & Soccer & 6 \\
\hline
\end{tabular}

Table 2 Oden classifications

Type1 SPR is elevated from the lateral
malleolus and FCR, but SPR is still
attached to the periosteum of the
fibula
SPR is torn free from its attachment
to the lateral malleolus
Aype2
avall fragment of the bone is
avulsed at the attachment of the
SPR
Type4
SPR is torn from its posterior attach-
ment and is usually lying deep to
the tendon

from the insertion on the malleolus with an avulsion of a small fragment of bone and those in which the SPR was torn at insertion or mid-substance were excluded from the indication criteria for the current procedure.

Imaging studies were performed for all the participants. Plain radiography and computed tomography (CT) revealed no bony fragments suggestive of avulsion fractures. Magnetic resonance imaging (MRI) revealed no tear in the peroneal longus and brevis tendons. The SPR and fibula periosteum were found detached from the fibula forming a false-pouch, while the fibrocartilaginous ridge remained intact (Fig. 1). Ultrasonographic (US) imaging also revealed the presence of false pouch and continuity of the SPR, and that the peroneal longus tendon could be dislocated from the bony groove (Fig. 2).

One patient experienced recurrent dislocation after undergoing a reattachment procedure twenty-eight years earlier.

\section{Operative technique}

The operations were performed under regional anaesthesia. The patient was placed in the lateral decubitus

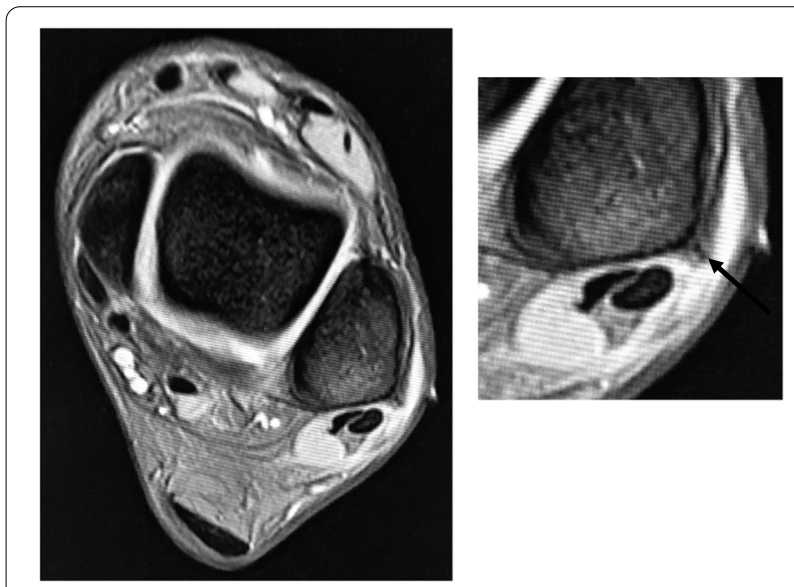

Fig. 1 Preoperative MRI (T2WI). MRI showing a formed false-pouch, although the fibrocartilaginous ridge (arrow) remains intact 

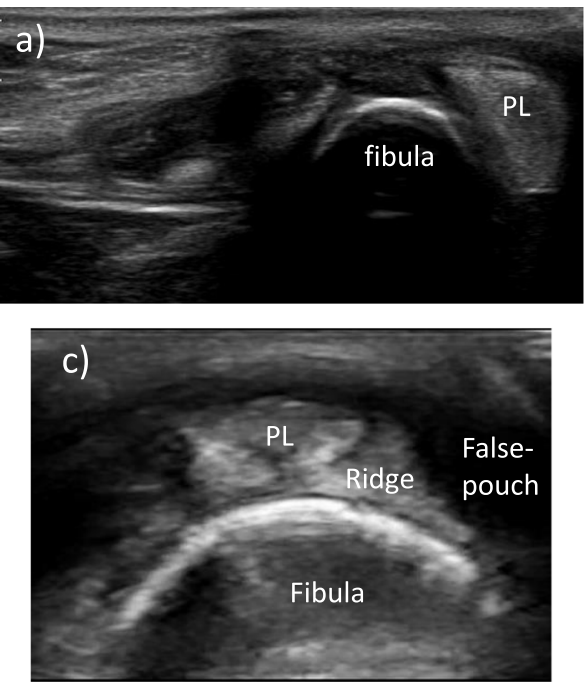

Fig. 2 Preoperative US image

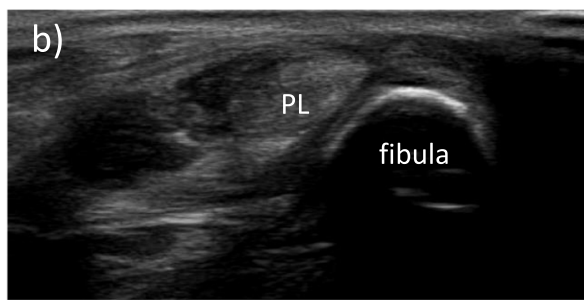

a) The peroneal longus tendon (PL) is dislocated into the false-pouch.

b) The peroneal longus tendon could be reduced to the peroneal groove.

c) A false-pouch is formed (low echoic area over the lateral malleolus), although the fibrocartilaginous ridge remains intact. position, and a pneumatic tourniquet was placed around the lower thigh.

Marks were made on the skin at the proximal and distal ends of the false pouch as determined by US imaging before the start of the operation. A longitudinal incision from the tip of the fibula to the proximal end of the false pouch, usually $3-4 \mathrm{~cm}$ long, was made over the lateral aspect of the fibula. The superior peroneal retinaculum was exposed, with usually no tear detected; however, the retinaculum and periosteum of the fibula were elevated off the fibula and had made a false pouch. The peroneal tendon, which was dislocated, was manually displaced to the false pouch. Small incisions were made at the proximal and distal ends of the false pouch, and from there, rasp was put into the false pouch to refresh the surface of fibula so that bleeding from the soft tissue would promote adhesion of the repaired retinaculum and periosteum to the fibula (Fig. 3). Suture tape was placed over the periosteum just anterior to the fibrocartilaginous ridge and fixed with 3 or 4 suture anchors (Fig. 4). For the first 6 cases, 3 suture anchors $(\phi 3.5-\mathrm{mm}$ DEX Swive Lock $^{\text {TM }}$; Arthrex, Naples, FL) were used to fix the 2-mm wide suture tape (Arthrex, Naples, FL). A suture anchor ( $1.6-\mathrm{mm}$ Fibre $\mathrm{Tak}^{\mathrm{TM}}$; Arthrex, Naples, FL) with a 1.3$\mathrm{mm}$ width suture tape (Arthrex, Naples, FL) was added at the tip of the fibula, and the other 3 suture anchors were changed to smaller-sized suture anchors $(\phi 2.5-\mathrm{mm}$ mini Push Lock ${ }^{\mathrm{TM}}$; Arthrex, Naples, FL) for the next 24 cases. A Fibre $\mathrm{Tak}^{\mathrm{TM}}$ anchor was inserted from the tip of the lateral malleolus in the direction of the fibula head, and the other 3 suture anchors were inserted in the lateral aspect of the fibula just anterior to the fibrocartilaginous ridge at an angle of $30^{\circ}$ against the lateral aspect of the fibula (Fig. 5) [9]. The suture tape was covered with

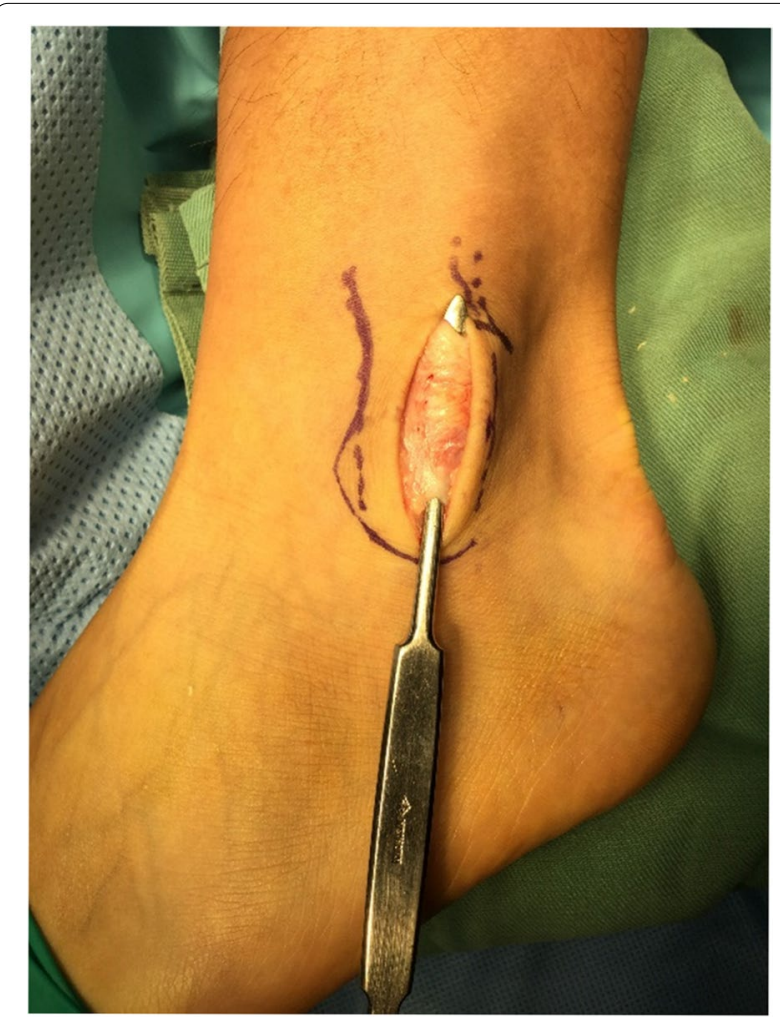

Fig. 3 Opening of the proximal and distal ends of the false-pouch. Small incisions are made at the proximal and distal ends of the false-pouch, and the surface of the fibula is rasped 

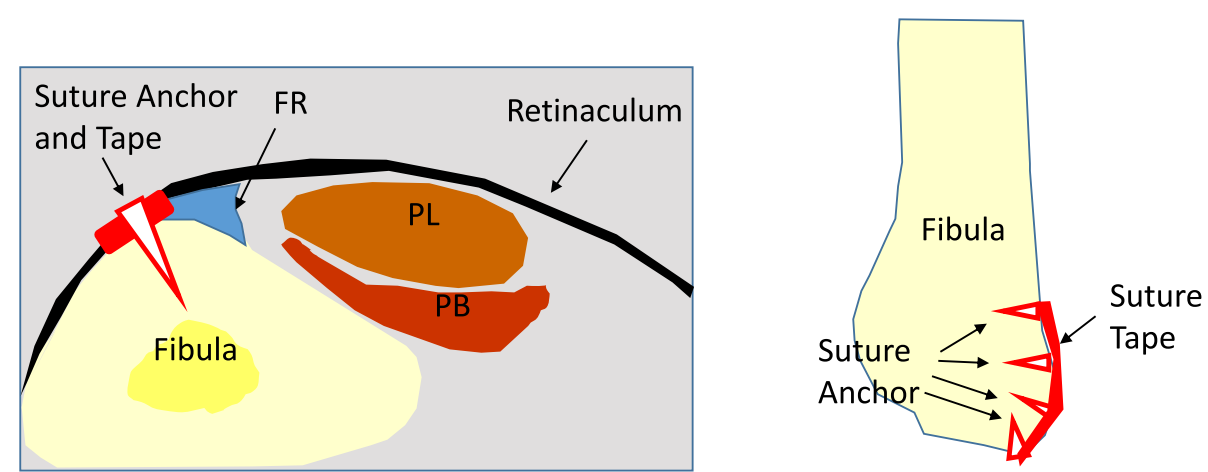

Fig. 4 Schema of fixation with suture tape. The suture tape is fixed with 3 or 4 suture anchors. The suture anchors are inserted just anterior to the fibrocartilaginous ridge (FR). PL: Peroneus longus tendon. PB: Peroneus brevis tendon

subcutaneous tissue, and the skin was closed routinely. Postoperative CT imaging revealed anchor positions and directions (Fig. 6).

\section{Postoperative management}

A short-leg cast in the neutral position of the ankle joint was applied for 2-3 weeks postoperatively. After cast removal, partial weight-bearing was permitted, and full weight-bearing was permitted at 2-4 weeks. Running was allowed after 4-6 weeks, and return to play at the pre-injury level was allowed after 10 weeks.

\section{Evaluation}

The American Orthopaedic Foot and Ankle Society (AOFAS) Ankle-Hind Foot score was evaluated preoperatively and at the last follow-up for the patients who were followed up for $>6$ months. The time to resume running and the rate and time to return to sports activity were recorded. The time to return to sports was defined as the time when the patient could return to the preoperative level of sports activity. The incidence rates of postoperative recurrent dislocation and other complications were also recorded.
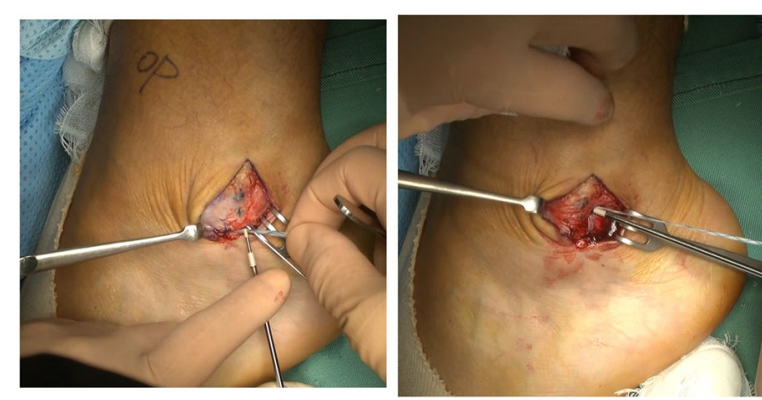

Fig. 5 Direction of the anchors inserted. First, the anchor is inserted from the tip of the lateral malleolus in the direction of the fibula head. (Left) Other three suture anchors are inserted at an angle of $30^{\circ}$ from the lateral aspect of the fibula. (Right)

\section{Statistical analysis}

The AOFAS scores before operation and at the last follow-up were compared using the paired Student $t$ test in Microsoft Excel 2013 (Microsoft Corp., Washington, USA). Significance was reported at the $95 \%$ confidence level $(p<0.05)$.

\section{Results}

One patient had a postoperative recurrent dislocation at 8 weeks from operation when joining a professional soccer team and trained to return to play, and underwent another operation for recurrent dislocation. Another patient did not return to the preoperative level of sports activity for reasons other than the ankle condition. The other 28 patients $(93.3 \%)$ were able to return to their preoperative level of sports activity without any major complications. The mean time to resume running was $8.0 \pm 2.8$ weeks (range: $3-12$ weeks) and time to return to sports was $14.4 \pm 3.2$ weeks (range: 10-24 weeks; Table 3 ). The AOFAS score was evaluated for 29 patients who did not undergo another operation for the peroneal tendon. The mean preoperative AOFAS score was $79.7 \pm 9.6$ (range: 41-90), which improved significantly to $98.9 \pm 3.2(87-100)$ postoperatively ( $p<0.01$; Fig. 7).

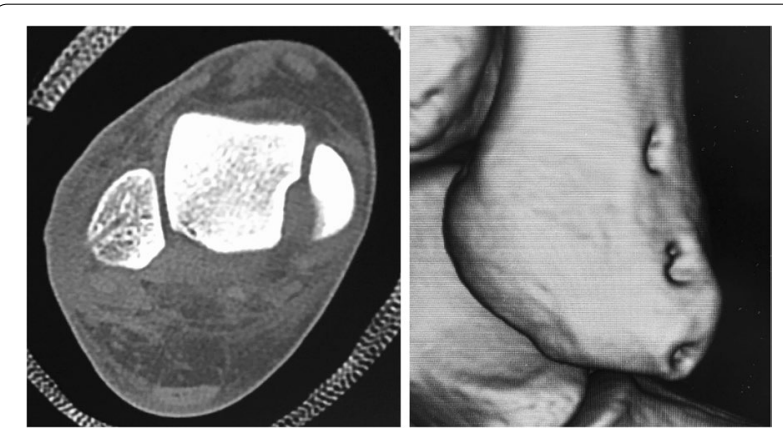

Fig. 6 Postoperative $\mathrm{CT}$ image. Postoperative $\mathrm{CT}$ image showing the position and direction of the anchor holes 
Table 3 Results

\begin{tabular}{|c|c|c|c|c|c|}
\hline Case & $\begin{array}{l}\text { Runnning } \\
\text { (weeks) }\end{array}$ & $\begin{array}{l}\text { Return } \\
\text { to play } \\
\text { (weeks) }\end{array}$ & Recurrence & $\begin{array}{l}\text { Pre AOFAS } \\
\text { scale score }\end{array}$ & $\begin{array}{l}\text { Post AOFAS } \\
\text { scale score }\end{array}$ \\
\hline 1 & 10 & 16 & - & 82 & 100 \\
\hline 2 & 8 & 16 & - & 41 & 87 \\
\hline 3 & 6 & - & + & 68 & - \\
\hline 4 & 12 & 15 & - & 85 & 100 \\
\hline 5 & 12 & 16 & - & 85 & 100 \\
\hline 6 & 8 & 14 & - & 82 & 100 \\
\hline 7 & 6 & 12 & - & 85 & 100 \\
\hline 8 & 10 & 18 & - & 72 & 90 \\
\hline 9 & 5 & 10 & - & 87 & 100 \\
\hline 10 & 12 & 24 & - & 87 & 100 \\
\hline 11 & 10 & 16 & - & 82 & 100 \\
\hline 12 & 12 & 20 & - & 80 & 100 \\
\hline 13 & 5 & 12 & - & 87 & 100 \\
\hline 14 & 6 & 12 & - & 78 & 92 \\
\hline 15 & 8 & 16 & - & 70 & 100 \\
\hline 16 & 4 & 10 & - & 73 & 100 \\
\hline 17 & 4 & 12 & - & 73 & 100 \\
\hline 18 & 3 & 12 & - & 87 & 100 \\
\hline 19 & 4 & 12 & - & 87 & 100 \\
\hline 20 & 8 & 12 & - & 87 & 100 \\
\hline 21 & 7 & 16 & - & 87 & 100 \\
\hline 22 & 6 & 12 & - & 74 & 100 \\
\hline 23 & 7 & - & - & 90 & 100 \\
\hline 24 & 12 & 15 & - & 79 & 100 \\
\hline 25 & 12 & 15 & - & 69 & 100 \\
\hline 26 & 8 & 12 & - & 85 & 100 \\
\hline 27 & 8 & 12 & - & 77 & 100 \\
\hline 28 & 8 & 16 & - & 87 & 100 \\
\hline 29 & 7 & 12 & - & 84 & 100 \\
\hline 30 & 11 & 19 & - & 69 & 100 \\
\hline
\end{tabular}

\section{Discussion}

The most important finding of the present study was that the SPR reattachment procedure with suture tape was a safe and effective procedure for treating the dislocation of the peroneal tendon.

Many types of surgical procedures for dislocation of the peroneal tendon have been reported, such as reattachment of the SPR $[1-3,5,6,12,18,23,24]$, bone block procedures $[7,10,15,24]$, groove deepening procedures $[2,8,27]$, rerouting procedures $[13,21]$, and tissue transfer procedures [16, 17]. Among these procedures, reattachment of the SPR is known as an anatomical and less invasive procedure.

The Das De procedure (Singapore operation) is a popular reattachment procedure and has been reported to have good clinical outcomes $[3,6]$. However, it is usually followed by 6 weeks of cast immobilization [3, 6], which is a major disadvantage of this procedure. Recently, the Das De procedure was modified by some surgeons and, thereafter, accelerated postoperative treatment $[1,2,4$, $5,10,12,18,23,26]$. The modified Das De procedure requires only one suture line on SPR to close the falsepouch and has the advantage of allowing repair while preserving the blood supply of the SPR compared to the original Das De procedure, which requires two suture lines [23, 24]. However, Cho et al. [2] and Deng et al. [5] mentioned that loose suturing of the SPR may cause postoperative recurrent dislocation.

There are some advantages of the current procedure to the traditional pouch closure technique. First, suture tape can be fixed to a wide area of the SPR. Further biomechanical studies are needed to confirm whether the current procedure can fix SPR more firmly to the bone than the previously reported false-pouch closure technique. Previous biomechanical studies have shown that a wider contact area with the suture bridge technique has superior time-zero structural properties in rotator cuff repair [20, 22].

Second, the current procedure does not require an incision to the SPR to improve healing through better preservation of the blood supply, and less peritendinous fibrosis will not cause tendon irritation and adherence after the operation. The endoscopic procedure also requires no incision to the SPR and is less invasive, though technically demanding and involves a steep learning curve $[11,18]$. Current procedure has advantage in ts ease of learning compared to endoscopic procedure.

Third, the suture anchor is knotless; therefore, the current technique is advantageous in areas with poor subcutaneous tissue, such as the area around the lateral aspect of the fibula. Suture tape also has a lower profile; thus, there should be no hardware irritation.

Care must be taken when inserting the anchors in the lateral malleolus. The fibula is a thin bone; therefore, a short small-diameter anchor is needed, this was the reason why the authors changed the suture anchors for the present cases.

The limitations of the current study include the fact that the follow-up period was too short to obtain the necessary follow-up clinical results and data on dislocation recurrence. Biomechanical studies are needed to investigate the strength of the initial fixation, identify the number of suture anchors that should be used, and the interval between suture anchors. Further studies are also needed to determine the optimal protocol for postoperative treatment. 


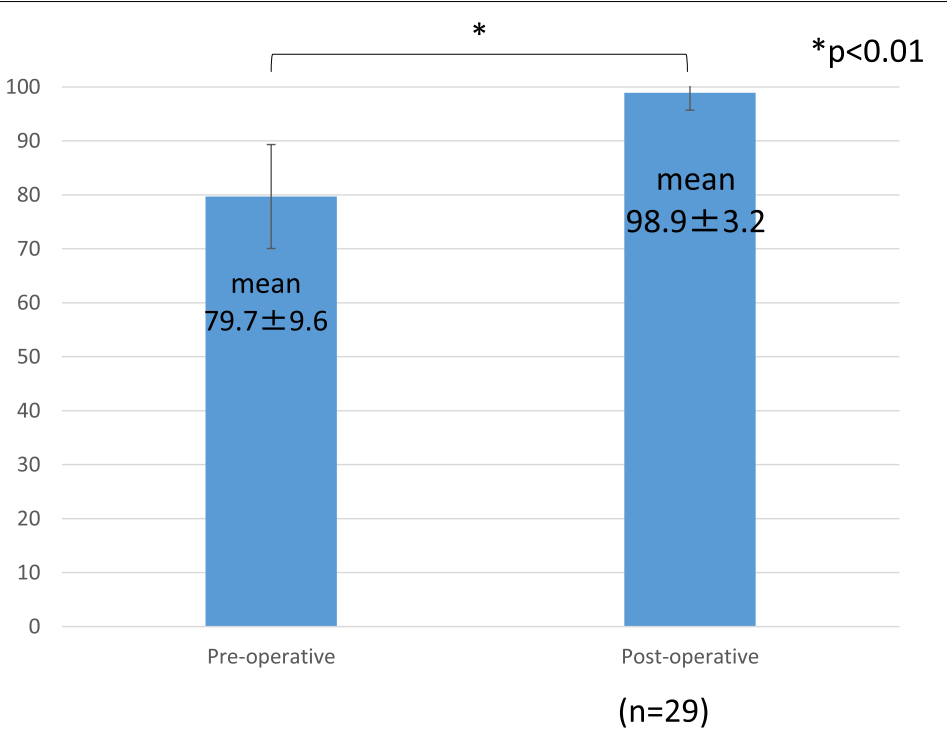

(except for 1 recurrent case )

Fig. 7 AOFAS Ankle-Hind Foot scale scores

\section{Conclusion}

A false-pouch closure technique with suture tape and anchors was described, which was found to have reliable results and to enable early return of patients to their sports activities.

\section{Abbreviations}

SPR: Superior peroneal retinaculum; CT: Computed tomography; MRI: Magnetic resonance imaging; US: Ultrasonography; AOFAS: American Orthopaedic Foot and Ankle Society.

\section{Acknowledgments}

The authors thank Editage (www.editage.com) for English language editing.

\section{Authors' contributions}

Contributed to the conception and design: Dr. Kumai. Carried out the patient's operation and acquisition of data: Dr. Kumai, Dr. Shinohara, Dr. Matsui, Dr. Kanzaki, Dr. Noguchi, and Dr. Tanaka. Responsibility for acquisition of data: Dr. Yabiku, Dr. Higashiyama. Analysis and critical interpretation of data, including review and evaluation of previous studies: Dr. Matsui and Dr. Sugimoto. Drafting the manuscript: Dr. Matsui. All authors read and approved the final manuscript.

\section{Funding}

No funding was received to conduct this study.

\section{Declarations}

\section{Ethics approval and consent to participate}

Ethics approval for the study was obtained from the ethics committee of Saiseikai Nara Hospital (ID: R-2), and the current study was conducted in accordance with the principles of the Declaration of Helsinki.

\section{Competing interests}

The authors have no conflicts of interest directly relevant to the contents of this article.

\section{Author details}

'Department of Orthopaedic Surgery, Saiseikai Nara Hospital, Nara, Japan. ${ }^{2}$ Faculty of Sports Sciences, Waseda University, 2-579-15 Mikajima, Tokorozawa city, Saitama, Japan. ${ }^{3}$ Faculty of Sport and Health Science, Ritsumeikan University, Kusatsu, Japan. ${ }^{4}$ Department of Orthopaedic Surgery, Kobe University Graduate School of Medicine, Kobe, Japan. ${ }^{5}$ Department of Orthopaedic Surgery, Kurume University Medical Center, Kurume, Japan. ${ }^{6}$ Department of Orthopaedic Surgery, Hyakutake Orthopaedic \& Sports Clinic, Saga, Japan. ${ }^{7}$ Department of Orthopaedic Surgery, Maki Orthopaedic Hospital, Osaka, Japan. ${ }^{8}$ Department of Orthopaedic Surgery, Matsukura Hospital, Nara, Japan.

Received: 15 January 2021 Accepted: 10 March 2021

Published online: 18 March 2021

\section{References}

1. Adachi N, Fukuhara K, Tanaka H, Nakasa T, Ochi M (2006) Superior retinaculoplasty for recurrent dislocation of peroneal tendons. Foot Ankle Int 27:1074-1078

2. Cho J, Kim JY, Song DG, Lee WC (2014) Comparison of outcome after retinaculum repair with and without fibular groove deepening for recurrent dislocation of the peroneal tendons. Foot Ankle Int 35:683-689

3. De Das S, Balasubramaniam P (1985) A repair operation for recurrent dislocation of peroneal tendons. J Bone Joint Surg 67:585-587

4. Davda K, Malhotra K, O'Donnell P, Singh D, Cullen N (2017) Peroneal tendon disorders. EFORT Open Rev 22:281-292

5. Deng E, Shi W, Jiao C, Xie X, Jiang D, Chen L et al (2019) Reattachment of the superior retinaculum versus the bone block procedure for the treatment of recurrent peroneal tendon dislocation: two safe and effective techniques. Knee Surg Sports Traumatol Arthrosc 27:2877-2883

6. Hui JH, De Das S, Balasubramaniam P (1998) The Singapore operation for recurrent dislocation of peroneal tendons: long-term results. J Bone Joint Surg Br 80:325-327

7. Kelly RE (1920) An operation for the chronic dislocation of the peroneal tendons. Br J Surg 7:502-504

8. Kollias SL, Ferkel RD (1997) Fibular grooving for recurrent peroneal tendon subluxation. Am J Sports Med 25:329-335 
9. Kumai T, Benjamin M (2003) The histological structure of the malleolar groove of the fibula in man: its direct bearing on the displacement of peroneal tendons and their surgical repair. J Anat 203:257-262

10. Larsen E, Flink-Olsen M, Seerup K (1984) Surgery for recurrent dislocation of the peroneal tendons. Acta Orthop Scand 55:554-555

11. Hau WWS, Lui TH, Ngai WK (2017) Endoscopic superior peroneal retinaculum reconstruction. Arthrosc Tech 18:e45-e51

12. Maffulli N, Ferran NA, Oliva F, Testa V (2006) Recurrent subluxation of the peroneal tendons. Am J Sports Med 34:986-992

13. Martens MA, Noyez JF, Mulier JC (1986) Recurrent dislocation of the peroneal tendons. Results of rerouting the tendons under the calcaneofibular ligament. Am J Sports Med 14:148-150

14. McLennan JG (1980) Treatment of acute and chronic luxations of the peroneal tendons. Am J Sports Med 8:432-436

15. Micheli LJ, Waters PM, Sanders DP (1989) Sliding fibular graft repair for chronic dislocation of the peroneal tendons. Am J Sports Med 17:68-71

16. Mick C, Lynch F (1987) Reconstruction of the peroneal retinaculum using the peroneus quartus. A case report. J Bone Joint Surg 69:296-297

17. Miyamoto W, Takao M, Komatsu F, Uchio Y (2007) Reconstruction of the superior peroneal retinaculum using an autologous gracilis tendon graft for chronic dislocation of the peroneal tendons accompanied by lateral instability of the ankle: technical note. Knee Surg Sports Traumatol Arthrosc 15:461-464

18. Nishimura A, Nakazora S, Ito N, Fukuda A, Kato K, Sudo A (2016) Tendoscopic double-row suture bridge peroneal retinaculum repair for recurrent dislocation of peroneal tendons in the ankle. Arthrosc Tech 2:e441-e446

19. Oden RR (1987) Tendon Injuries about the ankle resulting from skiing. Clin Orthop Relat Res 216:63-69

20. Park MC, Tibone JE, EIAttrache NS, Ahmad CS, Jun BJ, Lee TQ (2007) Part II: biomechanical assessment for a footprint-restoring transosseous-equivalent rotator cuff repair technique compared with a double-row repair technique. J Shoulder Elbow Surg 16:469-476

21. Poll R, Duijfes F (1984) The treatment of recurrent dislocation of the peroneal tendons. J Bone Joint Surg 66:98-100

22. Rossi LA, Rodeo SA, Chahla J, Ranalletta M (2019) Current concepts in rotator cuff repair techniques: biomechanical, functional, and structural outcomes. Orthop J Sports Med 20:2325967119868674

23. Saragas NP, Ferrao PN, Mayet Z, Eshraghi H (2016) Peroneal tendon dislocation/subluxation - case series and review of the literature. Foot Ankle Surg 22:125-130

24. Tomihara T, Shimada N, Yoshida G, Kaneda K, Matsuura T, Satake S (2010) Comparison of modified Das De procedure with Du Vries procedure for traumatic peroneal tendon dislocation. Arch Orthop Trauma Surg 130:1059-1063

25. van Dijk PA, Miller D, Calder J et al (2018) The ESSKA-AFAS international consensus statement on peroneal tendon pathologies. Knee Surg Sports Traumatol Arthrosc 26:3096-3107

26. van Dijk PA, Gianakos AL, Kerkhoffs GM, Kennedy JG (2016) Return to sports and clinical outcomes in patients treated for peroneal tendon dislocation: a systematic review. Knee Surg Sports Traumatol Arthrosc 24:1155-1164

27. Walther M, Morrison R, Mayer B (2009) Retromalleolar groove impaction for the treatment of unstable peroneal tendons. Am J Sports Med 37:191-194

\section{Publisher's Note}

Springer Nature remains neutral with regard to jurisdictional claims in published maps and institutional affiliations.

\section{Submit your manuscript to a SpringerOpen ${ }^{\circ}$ journal and benefit from:}

- Convenient online submission

- Rigorous peer review

- Open access: articles freely available online

- High visibility within the field

- Retaining the copyright to your article

Submit your next manuscript at $\mathbf{s p r i n g e r o p e n . c o m ~}$ 